\title{
La céramique d'habitat du Bronze final IIIb à La Tène A en Alsace et en Lorraine : essai de typo- chronologie
}

Cyril Marigny

\section{CpenEdition}

\section{Journals}

Édition électronique

URL : https://journals.openedition.org/rao/1872

DOI : $10.4000 /$ rao. 1872

ISBN : 978-2-7535-2790-4

ISSN : $1775-3732$

Éditeur

Presses universitaires de Rennes

\section{Édition imprimée}

Date de publication : 30 décembre 2012

Pagination : 323

ISBN : 978-2-7535-2641-9

ISSN : 0767-709X

\section{Référence électronique}

Cyril Marigny, "La céramique d'habitat du Bronze final IIIb à La Tène A en Alsace et en Lorraine : essai de typo-chronologie ", Revue archéologique de l'Ouest [En ligne], 29 | 2012, mis en ligne le 30 décembre 2012, consulté le 23 juillet 2021. URL : http://journals.openedition.org/rao/1872 ; DOI : https://doi.org/ $10.4000 /$ rao. 1872

Ce document a été généré automatiquement le 23 juillet 2021.

@ Presses universitaires de Rennes 


\title{
La céramique d'habitat du Bronze final IIIb à La Tène A en Alsace et en Lorraine : essai de typo-chronologie
}

\author{
Cyril Marigny
}

\section{RÉFÉRENCE}

Adam A.-M., Defressigne S., Koenig M.-P., Lasserre M. et coll., 2011 - La céramique d'habitat du Bronze final IIIb à La Tène A en Alsace et en Lorraine : essai de typochronologie, (Suppl. RAE 29), 2011, 344 p., ill. n.b. (ISBN 978-2-915544-17-6, 25 €). Adam A.-M. (dir.), 2005 - Recherches de protohistoire alsacienne : la céramique d'habitat du Bronze final III à La Tène ancienne. 23e supplément à la Revue archéologique de l'Est Dijon, SAE, 2005, 290 p., ill. N \& B. (ISBN : 2-915544-04-2 - ISSN : 1773-6773, $25 €)$.

1 La parution de l'ouvrage coordonné par A.-M. Adam, S. Defressigne, M.-P. Koening et M. Lasserre en 2011 sur la céramique d'habitat du Bronze final IIIb à La Tène A en Alsace et Lorraine est pour nous l'occasion de revenir sur un premier volume dirigé par A.-M. Adam en 2005 qui portait plus particulièrement sur l'Alsace et sur le même champ chronologique.

Ces deux ouvrages, très complémentaires tant sur la forme que sur le fond, offrent un véritable outil de travail pour qui s'intéresse à la typo-chronologie des assemblages céramiques de la protohistoire ancienne et plus particulièrement sur la tranche chronologique couvrant l'extrême fin du Bronze final jusqu'à La Tène ancienne. Plus que de simples présentation de lots céramiques, il s'agit là d'un véritable travail de fond mené à l'occasion d'un programme de recherches plus large (programme de l'UMR 7044, CNRS-Université Marc Bloch, Strasbourg) dont la réflexion portait sur le statut et la fonction des sites d'habitat hallstattiens du Nord-Est de la France. Le but des études présentées dans ces deux volumes était donc de construire un argumentaire 
permettant une approche comparative de la chronologie des sites, tout en permettant une meilleure caractérisation de leurs potentiels économiques et sociaux. Pour répondre à cette problématique, il a été nécessaire de développer un système descriptif et analytique normalisés, visant à une lecture homogène des ensembles mobiliers. Le référentiel typo-chronologique mis au point est alors testé sur plusieurs assemblages céramiques (corpus bien documentés ou très représentatifs, la plupart issus de fouilles préventives récentes) ouvrant sur des propositions évolutives des récipients, forme par forme, couplés à une étude détaillée de l'évolution des décors.

3 À l'issue de l'analyse, les auteurs proposent un séquençage de l'évolution morphologique et stylistique des vases sur la base des grandes phases chronologiques usuelles (BF IIIb, Ha C, Ha D1, Ha D2-D3, LT A) en fonction des variables géographiques de la zone d'étude. Il est ainsi possible de lire les grandes tendances typochronologiques de ce type mobilier (rythme, césure ou grands changements stylistiques) mais aussi de comprendre l'articulation entre les différents faciès culturels régionaux de l'Est de la France.

4 Deux livres essentiels donc pour les protohistoriens travaillant sur la tranche chronologique couvrant l'extrême fin du Bronze final jusqu'à La Tène ancienne. En espérant que ces ouvrages encouragent les autres régions de France à publier leurs données avec le même esprit de synthèse.

\section{AUTEURS}

\section{CYRIL MARIGNY}

Inrap Basse-Normandie - UMR 6566-CReAAH 